\title{
La unidad de la Iglesia. Su desarrollo en la eclesiología-biográfica de John Henry Newman (I)
}

\author{
Ricardo Miguel Mauti \\ Instituto Teológico Nuestra Señora de Guadalupe - Santa Fe - Argentina \\ ricardomauti@uca.edu.ar \\ Recibido 04.05.2020/ Aprobado 11.06.2020 \\ DOI: https://doi.org/10.46553/teo.57.133.2020.p77-94
}

\section{RESUMEN}

El artículo presenta la tesis doctoral defendida por el autor en diciembre de 2016, en la Facultad de Teología Santa María de los Buenos Aires de la Pontificia Universidad Católica Argentina, bajo la dirección de Fray Dr. Jorge A. Scampini op. El título: "La unidad de la Iglesia. Su desarrollo en la eclesiología-biográfica de John Henry Newman", es justificado desde dos tópicos unidad en desarrollo y eclesiología-biográfica. La tesis intenta, por una parte, superar una concepción estática de la propiedad de unidad en la Iglesia, que ha dominado en la eclesiología católica desde la contrarreforma y que ha imposibilitado el diálogo entre las iglesias; por otra parte, busca descubrir el desarrollo de la idea de unidad en el entramado existencial de la vida de Newman; mostrando las correspondencias y paradojas que se establecen en los dos períodos confesionales en los que vivió el autor (anglicano-católico).

Palabras clave: Newman; Iglesia; Unidad; Desarrollo; Eclesiología-biográfica

The Church's Unity. Its Development within the Biographical-Ecclesiology by John Henry Newman

\section{ABSTRACT}

The article presents the doctoral thesis which has been defended by its writer in December 2016, at the Faculty of Theology Santa Maria de los Buenos Aires belonging to the Pontifical Catholic University of Argentina, which is under Friar Dr. Jorge A. Scampini op.'s direction. Its title is "The Church's unity. Its development within the biographical-ecclesiology by John Henry Newman", is being justified by two

- El autor es Doctor en Teología por la Pontificia Universidad Católica Argentina y profesor de Teología Sistemática en el Instituto Teológico Nuestra Señora de Guadalupe de la Ciudad de Santa Fe (Rep. Argentina). 
topics: developing unity and biographical ecclesiology. The current thesis aims, on the one hand, to outstrip a static concept of the Church unity which has been dominating in the Catholic ecclesiology since the catholic Counter-Reformation and has also prevented the communication and dialogue between the different churches. On the other hand, it also aims to discover the development of the idea of unity within the existential framework of Newman's life, thus showing the similarities and paradoxes that have been established in the two confessional periods during which the author (an Anglican-Catholic) has lived.

Key words: New man; Church; Unity; Development; Biographical ecclesiology.

\section{Introducción}

La unidad de la Iglesia. Su desarrollo en la eclesiología-biográfica de John Henry Newman, es el título de mi tesis doctoral defendida en la Facultad de Teología Santa María de los Buenos Aires, de la Pontificia Universidad Católica Argentina, el 14 de diciembre de 2016, bajo la dirección de Fray Dr. Jorge A. Scampini op., y ante el tribunal evaluador formado por los Pbros. Drs. José Carlos Caamaño, Alberto Espezel y Hernán Giudice. ${ }^{1}$ El presente artículo es una presentación sintética del método, estructura y contenidos de la tesis. El proyecto fue elaborado desde la segunda mitad del año 2010, presentado en agosto de 2011, y aprobado por la comisión evaluadora constituida ad hoc (Dra. Virginia Azcuy y los Pbros. Drs. Gustavo Podestá y Osvaldo Santagada) en diciembre de ese año. El trabajo de investigación incluyó dos períodos de estancia en el Reino Unido, cinco meses en cada etapa: Birmingham/Oxford (2012-2013) y Londres (2014-2015). La etapa de redacción se concluyó en el verano de 2016. Luego de varias instancias de corrección, a comienzos de septiembre de 2016, finalmente se presentó el escrito en la secretaría de la Facultad.

1 *El autor es profesor en la Facultad de Teología de la Pontificia Universidad Católica Argentina.

La tesis fue publicada con el título: La unidad de la Iglesia en John Henry Newman (Buenos Aires: Agape, 2018), $528 \mathrm{pp}$. 


\section{Autor y tema en reciprocidad}

\subsection{La cuestión del método}

El tema merece algunas premisas en orden a su justificación, que intentaré enunciar brevemente siguiendo dos tópicos explícitos en el título, tales son: 1) unidad de la Iglesia en desarrollo y 2) eclesiología-biográfica. Es evidente que el campo en el que he trabajado es la eclesiología, área donde la teología se pregunta sobre la razón, la naturaleza, las cualidades y la misión de la Iglesia. Más acotado mi interés estuvo puesto en la propiedad de su unidad, desde una doble vertiente: en cuanto expresa la verdad de la Iglesia en su necesaria y vital referencia al misterio de Dios, y como signo paradójico de su credibilidad en el mundo. Sin embargo, es en el entramado de una vida, ligada por dos polos confesionales (anglicano y católico), desde dónde he querido pensar la unidad de la Iglesia, para lo cual, he recurrido a la clave hermenéutica de desarrollo, que Newman ha tematizado cuando debió fundamentar intelectualmente los propios planteos y dudas acerca de la confesionalidad de su fe. He trabajado pues, sobre un autor que ha descubierto la Iglesia en la pluriformidad de sus dimensiones constitutivas, pensando y orando, y que ha llevado la búsqueda de una fe razonable hasta el paroxismo de la conversión acontecida a la mitad de un camino. De la articulación de estos tópicos, que explicaré en breve, depende en gran medida el aporte de mi trabajo. En efecto, en cuanto a la unidad, he intentado captar su logos interno siguiendo el dinamismo que adquiere en la economía de la salvación, entendida como acción del Espíritu Santo sobre una comunidad, y que el autor ha descubierto en un itinerario personal de búsqueda, dando ocasión a una obra, que es a la vez, fuente de reflexión teológica, como así también testimonio elocuente de la acción de Dios, en un peregrino de la verdad. De este modo, al plantear el tema de la unidad, he querido situarme en un plano hermenéutico que contrasta con la concepción estática-objetiva, que dominó en tiempos de la apologética clásica cristalizando en la llamada via notarum, y que desde entonces, aún con sus innegables 
aportes, ha condicionado la autocomprensión de la unidad de la Iglesia desde una óptica predominantemente extrínseca. ${ }^{2}$

Esta "unidad en desarrollo", intento verla reflejada en lo que denomino eclesiología-biográfica, concepto que he tomado y adaptado de otro más amplio y fundante en la teología contemporánea, como es el de teología biográfica. ${ }^{3}$ Una de las motivaciones que se halla en los orígenes de mi tesis, es el convencimiento de que en muchas propuestas teológicas subyace actualmente cierto déficit de experiencia. ${ }^{4}$ He querido por ello, orientar mi trabajo como un aporte más en la recuperación de esta cualidad, que permita superar ese cisma entre dogmática e historia vital; y reconociendo aquella verdad que ya Lutero señala, cuando dice: experientia facit theologum, he buscado integrar esta cualidad en la ratio teológica, ${ }^{6}$ cuando he tenido que pensar la eclesiología desde unos parámetros que no son tal vez los habituales. Con estas aclaraciones preliminares queda bosquejado el encuadre general al tema de mi investigación.

2 Cf. Avery Dulles, Models of the Church (New York: Image Book 2002) 32.

3 El método de la "teología biográfica", me fue descubierto por la Dra. Virginia R. Azcuy en 2008, cuando preparaba mi tesina de licenciatura. En el proyecto de tesis doctoral (2011) lo asumí definitivamente, y agradezco sus inmensos aportes como miembro del tribunal evaluador. En lo sustancial he seguido a Johann Baptist Metz, cuando expresa: «¿Qué aspecto debería presentar una teología que lograra acabar con este cisma entre dogmática e historia vital y volver a recomponer con impulso creador lo que lleva tanto tiempo disociado? En un intento de definirla, subrayando sobre todo su intención, yo llamaría a esta teología 'dogmática histórico-vital', una especie de biografía existencial teológica, entendiendo por biografía, no el simple reflejo literario de la subjetividad, para obtener en ese reflejo (dicho con palabras de Goethe) un símbolo interpretativo del mundo y de la vida. Semejante teología debe llamarse biografía, porque inscribe en la doxología de la fe la biografía mística de la experiencia religiosa, de la historia personal ante el rostro velado de Dios. Es biográfica, también, porque no es una teología deductiva por sistema, dispuesta a conquistar su aceptación e irrefutabilidad al precio de la tautología, sino una narración de la historia personal ante Dios, abreviada y condensada conceptualmente»: "¿Teología como biografía?», en Johann Baptist Metz, La fe en la historia y en la sociedad (Madrid: Cristiandad, 1979), 228-236.

$4 \mathrm{Cf}$. Ricardo M. Mauti, «La 'experiencia religiosa' forjadora de un lenguaje significativo en John Henry Newman», Teología 103 (2010): 133-154.

5 Citado según Gerhard Ebeling, Die Klage über das Erfahrungsdefizit in der Theologie als Frage nach ihrer Sache, en lbid., Wort und Glaube, vol. III, Tübingen 1975, 3-28; extraído de Michael Schneider, Teología como biografía. Una fundamentación dogmática, (Bilbao: Desclée de Brouwer, 2000), 12

6 Cf. Ricardo M. Mauti, «John Henry Newman y el talante autobiográfico de su teología», en Sociedad Argentina de Teología, Dar razón de nuestra esperanza. El anuncio del Evangelio en una sociedad plural, (Buenos Aires: Agape 2012), 261-270. 


\subsection{El marco histórico-teológico}

He trabajado sobre un autor cuya vida cubre el amplio arco del siglo XIX inglés, y que ha repartido su existencia en dos momentos confesionales temporalmente iguales. ${ }^{7}$ Nacido en Londres en 1801 en el seno del anglicanismo donde ejerció el ministerio pastoral, pasó a la Iglesia católica en 1845, donde fue ordenado sacerdote años más tarde fundando el Oratorio en Birmingham, lugar de su muerte en 1890. El itinerario que Newman recorre hacia el descubrimiento de la unidad en la catolicidad, constituye el lugar teológico donde se gesta un patrimonio doctrinal vasto y complejo, sea por las múltiples circunstancias que le dieron origen, por la fertilidad de sus ideas, como por la variedad de formas literarias con que las ha transmitido. ${ }^{8}$ Uno de los primeros problemas que debí enfrentar al formular la hipótesis de trabajo, fue: dónde descubrir el aporte sustancial que el autor hace a la eclesiología. La disyuntiva de tener que optar por uno de los dos períodos confesionales se me imponía como posibilidad viable, dado que el encuadre de su obra anglicano-católica, estaba dada por él mismo en la periodización de su autobiografía. ${ }^{9}$

Durante el tímido despertar de la investigación newmaniana en campo eclesiológico a finales de los años $50^{\prime},{ }^{10}$ y que comenzó a fraguar recién en el posconcilio, algunos especialistas intentaron acceder por ese camino: Edward Miller, p.ej., trabajó sobre la idea de Iglesia básicamente en la obra Via Media (1837) y James Tolhurst, por su parte, se dedicó a la noción de “comunión' centrándose en su predicación anglicana (1825-1843). ${ }^{11}$ En mi caso, la pregunta sobre

7 Cf. Louis Bouyer, Newman. His Life and Spirituality (New York: Kenedy \& Sons, 1958).

$8 \mathrm{Cf}$. Ricardo M. Mauti, Newman peregrino de la verdad. Un camino teológico-espiritual, (Buenos Aires: Agape 2011).

9 Puede verse la amplia justificación de este argumento en la sección «Newman en sus biógrafos», I Parte, C. II, 1-3.

10 Al final de los años 50', Stanley Jaki escribía: "Newman's vision of the Church has not been subjected to any systematic elaboration", Stanley Jaki, Les tendances nouvelles de l'Ecclesiologie, (Rome: Casa Editrice Herder, 1957), 35-35.

11 A modo de ejemplo, y dado el valor de ambos aportes, menciono dos obras publicadas a mediados de los 70' y finales de los 80': E. J. Miller, John Henry Newman on the idea of Church, (West Virginia: The Patmos Press, Shepherdstown, 1987); J. Tolhurst, The Church a Communion, in the preaching and thought of John Henry Newman, (Leominster: Gracewing, 1988). 
el "lugar" de la eclesiología newmaniana no podía librarme de su biografía, en cuanto que su teología se presenta invariablemente en referencia a circunstancias vitales totales, como intentaré demostrar en el curso de mi exposición. ${ }^{12}$ La opción por la cualidad de unidad, me permitía una integración de ambos períodos pero me enfrentaba al desafío de tener que abordar su obra entera, al modo de una empinada montaña que se levanta desafiante ante quien la observa. La imagen puede resultar ilustrativa; el recurso al alpinismo como metáfora antropológica -para decirlo con Ghislain Lafont-, me permitió descubrir que las rutas de acceso a una obra teológica, son variadas y algunas incluso, aparentemente intransitables por lo intrincado de sus propuestas y formulaciones; aquí me fue indispensable, casi como exigencia de método, cierta intuición y empatía con el camino que debía elegir y una cuota no menor de audacia, una vez que lo hube tomado, para sostenerme dentro del objetivo que me había propuesto. ${ }^{13}$ Frente a esta coyuntura opté en mi investigación por trabajar sobre el entero corpus de su obra, que abarca una amplia variedad de géneros literarios (ensayos, sermones, cartas, poesías y conferencias), desde los cuales, a la manera de un mosaico puede captarse su comprensión de la Iglesia. He intentado trazar el iter que recorren sus planteos, buscando descubrir el modo con que la idea de Iglesia fue creciendo en el autor, integrando los diversos elementos que componen su unidad. En este sentido, mi opción metódica es primeramente genético-diacrónica. Sin embargo, en la exposición de los desarrollos doctrinales no me he limitado a buscar solo las certezas con que Newman fundamenta sus opciones. El momento sincrónico del método, lo he aplicado al integrar estos datos en una comprensión asimilable de su aporte, en lo que considero puede constituir un esbozo de su eclesiología sistematizada desde la unidad.

12 Esta es la razón del amplio uso que hago de su monumental epistolario: John Henry Newman, The Letters and Diaries, (Oxford: University Press, 1978-2008); aprox. 20.000 cartas recogidas en 32 volúmenes.

13 Cf. Ghislain Lafont, Dios el tiempo y el ser, (Salamanca: Sígueme 1991), 347-348. Entre las devoluciones que me fueran dadas por los examinadores en la presentación del proyecto, rescato en esta línea, como estímulo y desafío, la del Pbro. Dr. Gustavo Podestá, cuando al referirse al programa total, habla de "ambicioso proyecto" (Informe 15/8/2011). 
En mi interés por abordar las ideas eclesiológicas de Newman, he buscado superar dos límites que tal vez, impidieron en el pasado una mejor recepción de su pensamiento, ${ }^{14}$ y que habría permitido una valoración más integral y situada de su obra: 1) el elemento histórico/cultural/eclesial, y 2) el desarrollo y la forma de su teología. En primer lugar, es evidente que trabajar sobre un autor inglés del siglo XIX, implicaba una atención esmerada a su época como a las raíces de su pensar, con marcos contextuales de carácter histórico, que permitiese alcanzar una correcta comprensión de la fisonomía propia de su teología. En segundo lugar, atender al momento evolutivo de su concepción de unidad, me exigía utilizar un instrumental apropiado que respondiera al espíritu con que el autor ha logrado su autocomprensión de la Iglesia y que he tomado de su 'ensayo sobre el desarrollo de las doctrinas', aplicándolo a su propia biografía-teológica.

Si tuviera que enunciar en una línea directriz su eclesiología, diría que, la Iglesia se presenta como una realidad paradójica. Así parece sintetizarlo en un pasaje de la Via Media que tiene amplias resonancias en su obra y que he citado en el exergo: «La Iglesia presenta una admirable coherencia y unidad de sus palabras y actos como característica general, pero marcada y desacredita de vez en cuando por anomalías manifiestas que requieren, y exigen, por nuestra parte el ejercicio de la fe». ${ }^{15}$ Esta correspondencia entre lo que constituye una admirable coherencia en la unidad, pero marcada y desacredita en su devenir histórico, es tal vez, el rasgo más impresionante de la captación que Newman tiene de la Iglesia. Mi intención ha sido poner a la luz, los espacios vitales-teológicos, en que esta paradoja se resuelve, señalando sus consecuencias existenciales, como también la posibilidad de un aporte perenne a la eclesiología. Teniendo delante este horizonte, a continuación, describiré

14 Para esta cuestión remito a nuestra contribución donde analizo la 'recepción' de su pensamiento en autores pre y posconciliares: Ricardo M. Mauti, «La recepción de Newman en la teología del siglo $X X_{»}$, Teología 87 (2005): 41 7-462.

15 VM 57. 
sintéticamente la estructura (1), destacaré los grandes ejes temáticos (2), mostraré la articulación teológica de estos ejes (3), esbozaré el carácter católico de la unidad (4) y resumiré sus implicaciones en unas conclusiones generales (5).

\subsection{La estructura}

En una visualización general, la tesis se estructura en tres partes, articuladas en nueve capítulos, con treinta y dos subtítulos, 332 págs., y un total de 1391 citas. Está enmarcada por una amplia introducción donde se justifica: elección del tema, implicación de la investigación, originalidad del aporte, explicitación del método, estructura y fuentes y unas conclusiones generales abiertas.

1) La primera parte: "La eclesiología anglicana del siglo XIX", integrada por tres capítulos, constituye una introducción a una de las etapas de particular relieve de la teología anglosajona, de la que Olegario G. de Cardedal, no ha dejado de alertar acerca de su inexplicable olvido. ${ }^{16}$ En primer lugar me detengo en el Movimiento de Oxford, acontecimiento determinante en la historia de la teología inglesa, en lo que significó el último fruto de la vieja tradición anglicana, que en teólogos como R. Hooker, W. Laud y los Carolinos, pero también J. Butler, L. Andrewes y toda la tradición High Church, supuso como intento de llevar a la Iglesia de Inglaterra de su aislamiento espiritual al contacto con las grandes corrientes de la cultura occidental y del catolicismo. ${ }^{17}$ Aquí planteo el escenario del movimiento tractariano y presento a sus actores, me detengo especialmente en sus líderes (J. Keble, H. Froude, E. Pusey), de quienes muestro sus perfiles religiosos en lo que contribuyeron como aporte de ideas. A través de este bosquejo donde confluyen múltiples corrientes, intento delinear desde una interpretación sinfóni-

16 Cf. Olegario G. de Cardedal, La Teología en España (1959-2009), (Madrid: Encuentro $2010), 487$.

17 Cf. Owen Chadwick, The Spirit of the Oxford Movement. Tractarian Essays, (Cambridge: Cambridge University Press, 1992). 
ca de autores clásicos y modernos, un 'retrato teológico-espiritual' del movimiento, tal como quedó grabado en la conciencia popular y en cierto modo fijado en la tradición anglicana. La importancia histórica que reviste en el seno del anglicanismo el surgimiento y desarrollo del Movimiento de Oxford con sus ansias de reforma, en el espíritu de "vuelta a las fuentes", puede expresarse en una formulación sintética como: un esfuerzo por distanciarse del protestantismo, recuperando el catolicismo, pero cuidándose al mismo tiempo de todo romanismo.

En segundo lugar, presento al autor que es la fuente primaria de mi tesis, al que busco acercarme desde una mirada histórico-eclesial. Para ello me detengo en la historia y recepción de su biografía a través de una lectura crítica de sus mejores exponentes (desde Hutton, Abbott, Brémond y Ward, hasta Trevor, Bouyer, Gilley, Blehl, Dessain y Ker), y muestro la variedad de 'retratos' con que fue transmitida su figura y la incidencia que esto ha tenido en la asimilación de su pensamiento. ${ }^{18}$

A partir de esta mirada a la historia de su biografía, ensayo una semblanza teológica del autor, recurro a algunos hitos significativos de su vida que ayudaron a configurar los desarrollos embrionarios de su reflexión eclesiológica (ej., tradición evangélica, ministerio anglicano, la poesía del Meditarráneo, que significó el primer contacto con tradiciones eclesiales no anglicanas, en particular la Iglesia romana, y de la que intento hacer una lectura teológica). Concluyo la primera parte, planteando la cuestión de las "fuentes" de su eclesiología, con una triple atención a la Sagrada Escritura, la Tradición (especialmente los Padres de la Iglesia) y a su

18 Este punto tiene ante todo una intención teológica dada la variedad de 'retratos' que ha adoptado el personaje, en las relecturas de su biografía: desde el Newman "liberal" adoptado por algunos de los máximos exponentes de la teología modernista (ej. Loisy, Tyrrell y Renan) hasta el Newman "ultramontano" (representado por W. Ward: de los 35 capítulos que componen su monumental The Life of John Henry Cardinal Newman, London, 1912, en dos volúmenes; solo 2 capítulos están dedicados a la etapa anglicana), en cierto modo, esta obra ha canonizado la imagen de un "Newman paladín de la ortodoxia católico-romana", que ha encontrado un lugar destacado en grupos conservadores dentro de la Iglesia católica. 
propia biografía como instancia hermenéutica de autocomprensión del dato revelado.

2) La segunda parte: "La unidad de la Iglesia en la etapa anglicana", es como el primer cuadro del díptico que compone el núcleo de la tesis. En tres capítulos presento el tema de la unidad en las grandes obras anglicanas, desde la Via Media $(1837)^{19}$ y algunos planteos previos (eclesiología de los PPS 1834-1837), hasta las Conferencias sobre la doctrina de la Justificación (1838). ${ }^{20}$ En este segmento me centro en obras que corresponden al estadio maduro de su teología anglicana y que cubren poco más de una década, inscrita dentro del marco más amplio del apogeo del movimiento tractariano. ${ }^{21}$ Puede decirse, que en esta etapa es donde Newman sienta las bases de su eclesiología en cuestiones como: relación Escritura-Tradición, doctrina de la justificación, visión sacramental y dimensión pneumatológica; temas que tendrán luego desarrollos significativos y que buscaran su inserción en el sistema católico, pero que aquí encuentran su referencia fundamental. A partir de aquí me detengo en un extenso capítulo que denomino "período de inflexión", donde intento verificar la crisis de su pensamiento, trazando dos polos reflexivos: uno geográfico-teológico (simbolizado en Littlemore, ${ }^{22}$ "lugar testigo" de sus dudas hacia el anglicanismo como de sus nuevos planteos hacia la Iglesia romana), el otro polo teológico-práctico (simbolizado en tres escritos: The Protestant idea of Antichrist de 1840, ${ }^{23}$ el Tract 90 de 1841, un intento de relectura de los 39 artículos en clave católica, y el último de los University Sermons titulado 'Teoría del desarrollo doctrinal' de 1843, que es una especie

19 El título original «Conferencias sobre la función profética de la Iglesia considerada en relación con el sistema romano y con el protestantismo popular».

20 El gran teólogo de Tubinga Johann Adam Möhler escribe entre 1825 y 1838 sus dos grandes obras: La unidad de la Iglesia y Simbólica.

21 Cf. Geoffrey Rowell, «Newman and the Anglican Tradition: Reflections on Tractarianism and the Seventeenth-Century Anglican Divines», Louvain Studies 15 (1990): 136-150.

22 La pequeña aldea de Oxfordshire.

23 Un escrito donde Newman justifica la deficiencia del principio teológico sobre el que habitualmente se ha basado el ataque contra Roma; sostiene que la Iglesia anglicana nunca ha considerado cuál es la esencia del "anticristo", con lo cual no ha podido demostrar estar libre de las acusaciones lanzadas contra Roma (p. 180). 
de "proyecto de ideas" que sirven de base para la arquitectura de su Essay of Development). El intento por dar un sistema teológico al anglicanismo en lo que se denomina Via Media, comienza a agrietarse lentamente en la medida en que crece su comprensión de los Padres de la Iglesia, a quienes lee por segunda vez en esta etapa, teniendo ante sí los cuadros históricos de la Iglesia antigua en la unidad de sus confesiones de fe y de las iglesias anglicana y romana en sus respectivas formulaciones. Este bagaje doctrinal de su eclesiología lo recojo en el capítulo VI, que cierra la segunda parte y que de manera intencional he denominado "La unidad bajo la idea de desarrollo". Aquí analizo su correspondencia de 1843 a 1845 en dos registros: familiar y académico, en lo que constituye la mayor explicitación de sus dificultades para alcanzar el estado de certeza acerca de la unidad de la Iglesia. ${ }^{24} \mathrm{Y}$ me detengo en el Ensayo sobre el desarrollo de las doctrinas, una obra que puede comprenderse como 'relectura' de sus posturas en la Via Media, pero que al mismo tiempo testimonia el proceso interior que llevó a su autor, desde una desconfianza radical hacia las doctrinas católicas por considerarlas corrupciones de la doctrina apostólica, a abrazarlas con certeza cuando pudo ver que en ellas se encontraban incorruptas aunque desarrolladas las doctrinas de fe..$^{25}$

24 Nunca más aplicable a este momento de su biografía-teológica aquellas palabras que testimonia en su Apología, cuando dice: «Quiero que se me conozca como un hombre de carne y hueso, y no como el maniquí que se viste de mis ropas» (Apo 12).

25 Los siete criterios del progreso de los dogmas:

1) Permanencia del tipo: es decir, permanencia de la forma fundamental de las proporciones y relaciones de las partes y aspectos del todo. Cuando permanece la estructura de conjunto, puede seguir manteniéndose el tipo, incluso si se cambian conceptos concretos.

2) Continuidad de principios: las diversas doctrinas representan principios que cada vez están más profundos, aunque a veces sólo se los conoce posteriormente.

3) Poder de asimilación: una idea que es viva, manifiesta su fuerza cuando se muestra capaz de penetrar la realidad, de asimilar otras ideas, de estimular el pensamiento y de desarrollarse sin perder su unidad interna. Esta fuerza de integración es un criterio del desarrollo legítimo.

4) Consecuencia lógica: El desarrollo dogmático es un proceso vital demasiado amplio para poder ser entendido meramente como explicación y deducción lógica a partir de premisas previas. Sin embargo, tiene que legitimarse posteriormente como lógicamente coherente.

5) Anticipación del futuro: tendencias que sólo más tarde se imponen y tienen repercusión, pueden hacerse notar ya mucho antes de modo aislado y poco nítido. Tales anticipaciones son signo de que la evolución posterior concuerda con la idea primitiva.

6) Influjo conservador sobre el pasado: un desarrollo, es una corrupción si contradice a la doctrina primitiva; un verdadero desarrollo mantiene y conserva los desarrollos previos. 
3) La tercera parte: "La unidad de la Iglesia en la etapa católica" es el otro cuadro del díptico. Para respetar la cronología de su vida expresada en su teología, dedico igualmente tres capítulos, en los que recorro con una lectura diacrónico-sincrónica, la cuestión de la unidad a través de las principales obras católicas: analizo los Discursos para auditorios mixtos (motivos de credibilidad de la Iglesia católica) y su artículo sobre la Consulta a los fieles laicos (1859), y dedico particular atención al oratorio inglés, en lo que tiene de significado como esfuerzo de inculturación y adaptación a su idea de unidad eclesial. Paso luego a los escritos de controversia: en Present position of catholics in England (1851), ${ }^{26}$ analizo la cuestión del 'prejuicio' confesional como obstáculo para la unidad; en la Carta a Pusey (1866) respuesta de Newman a su Eirenicon, muestro las dificultades de los anglicanos entorno a la mariología y los posibles caminos abiertos al diálogo; me detengo por último en el evento del Vaticano I, y las posiciones contrastantes de Manning y Newman, en torno al dogma de la infalibilidad papal. En el último capítulo realizo una inclusión desde la revisión que el propio Newman hace de su pensamiento, e intento una sistematización de sus principales aportes en diálogo con la teología contemporánea, en lo que ha habido de recepción de sus ideas eclesiológicas.

\section{Los grandes ejes temáticos}

La tesis en su conjunto, dentro de la complejidad creada por la diversidad de fuentes, en gran parte autobiográficas, presenta sin embargo, una fisonomía simple en los ejes que constituyen los fundamentos de su estructura, que en gran medida vienen dados por la continuidad de los problemas teológicos que acompañan la biogra-

7) Fuerza vital duradera: una corrupción conduce a la disolución y no puede tener una larga permanencia; por el contrario una fuerza vital duradera es un criterio a favor de que un desarrollo es fiel.

26 Las Conferencias sobre la situación de los católicos en Inglaterra (1851). 
fía del autor. ${ }^{27}$ En este sentido, subyace en su obra una afirmación hecha en el prólogo católico de su VM: «mi cometido a lo largo de la vida no ha sido pensar ni defender a la Iglesia católica contra toda clase de impugnadores, sino contra uno solo, es decir, yo mismo». ${ }^{28}$

¿Cuáles son los ejes que vertebran los principales planteos eclesiológicos?

\subsection{Carácter sacramental y dogmático}

Newman debe mucho a la teología inglesa del siglo XVIII, en particular un autor que lo ha marcado es J. Butler (obispo de Durham) y su obra Analogy of religion (1736), de ella recibe tres ideas fundamentales: la inserción de la existencia en una Iglesia visible, la necesidad de una religión exterior, y el carácter histórico de la revelación. A partir de estas ideas desarrolla dos principios que sustentan todo su sistema teológico: el principio sacramental, que entiende como la doctrina que reconoce que los fenómenos materiales son a la vez tipos e instrumentos de cosas reales e invisibles, ${ }^{29}$ y el principio dogmático, que es aquella doctrina que descubre la revelación como verdad objetiva, y que la Iglesia recibe por tradición y reconoce en un sistema de proposiciones (símbolos) y que interpreta según los criterios de: 'permanencia del tipo', 'continuidad de principios', e 'influjos conservador del pasado'.$^{30}$ Ambos principios (sacramental y dogmático) se distinguen por su naturaleza: el segundo mira al contenido objetivo de la verdad, mientras que el primero, se refiere a la forma de su comunicación. Sin embargo, en el misterio de la economía salvífica presentan una unidad de 'contraste', aquello

27 La segunda de las notas de los desarrollos legítimos "continuidad de principios" es aplicable en este caso.

28 VM 53.

29 Esta doctrina según Newman, abarca en su plenitud lo que anglicanos y católicos creen acerca de los sacramentos, el artículo de la comunión de los santos, como de los misterios de la fe.

30 Son las notas 1, 2 y 6 de los desarrollos legítimos: "Dogma" en la mente de Newman equivale al «realismo de lo que Dios ha realizado y nos ha comunicado para nuestra salvación». La fe es dogmática en el sentido que es la 'presencia de hechos reales, afirmados en proposiciones verdaderas' (VM 239). 
que John Crosby denomina coincidentia oppositorum, expresión que revela la quintaesencia de su comprensión del dogma; dice en el Ensayo: «a un aspecto de la revelación no debe permitírsele excluir u obscurecer a otro: el cristianismo es dogmático, devocional y práctico, todo a la vez, exotérico y esotérico, es indulgente y estricto, es luminoso y oscuro, es amor y es temor» $(D e v){ }^{31}$

\subsection{Carácter escatológico e histórico}

En la eclesiología newmaniana la unidad tiene una dimensión esencialmente escatológica e histórica, fruto de sus abundantes lecturas de los Padres. ${ }^{32}$ En el período anglicano, en su obra Via Media (1837) y en Development (1845), ${ }^{33}$ como también en el período católico, en sus Mixed Congregations (1849) ${ }^{34}$ y en la Carta al Duque de Norfolk (1874) se evidencia que la Iglesia se encuentra entre el ya y el todavía no. En su unidad la Iglesia es la anticipación de la plenitud escatológica para cuya concreta realización aún se encuentra en camino. Los sermones anglicanos (en particular el período que analizo entre 1834-1837) ${ }^{35}$ y que son retomados sustancialmente en las obras anteriormente citadas, constituyen una síntesis del esquema promesa-cumplimiento. Se entiende por qué el uso recurrente que Newman hace del AT, que lee en clave cristológica, sacando consecuencias que permiten descubrir por un lado, las raíces veterotestamentarias de la Iglesia, en temas como: pueblo mediador, universalismo salvífico, y relación individuo-comunidad, y por otro, la novedad de la comunidad del NT, obra del Dios trinitario, que

31 Cf. John F. Crosby, «Newman come Intelletto imperiale. La comprensività della sua mente e del suo cuore», en V. F. Blehl, J. M. Cameron y AA. VV., John Henry Newman. L'idea di ragione, (Milano: Jaca Book, 1992), 159.

32 Cf. Michael U. Lang, "Newman and the Fathers of the Church", New Blackfriars 92 (2011) 147-156.

33 En el Ensayo sobre el Desarrollo de las doctrinas el tema escatología-historia es recurrente para hacer notar la dinámica del desarrollo que distingue entre idea y formulación.

34 Sus Discursos para auditorios mixtos (1849).

35 Período que corresponde a la primera etapa del movimiento tractariano. En particular el sermón Steadfastness in old Paths ('confianza en los antiguos caminos', perseverancia en la tradición) PPS VII, 18. 
funda su visibilidad en la encarnación del Verbo, constituida permanentemente en la dinámica del Espíritu como autorrevelación de Dios en Jesucristo. ${ }^{36}$

\subsection{Carácter jurídico-institucional}

Newman sostuvo siempre que el sermón National Apostasy, predicado por J. Keble en 1833 había marcado el nacimiento del Movimiento de Oxford. En esta dirección hay que señalar que, una de las causas que dieron origen al movimiento tractariano fue la relajación de la disciplina eclesial, con sus síntomas de alarma como: pérdida del sentido de lo sagrado, abandono pastoral, confusión en torno al principio de autoridad, creciente tendencia al erastianismo. ${ }^{37}$ Si bien es cierto que Newman no se interesó por el derecho canónico en el sentido que le damos actualmente, y que no ha tenido intención de elaborar una teología del derecho eclesial, como si parece que la tuvo J. A. Möhler en sus artículos para la Theologische Quartalschrift (1823); ${ }^{38}$ sin embargo, sus ideas sobre la función teológica del derecho y su servicio a la comunión, son numerosas y fértiles y aparecen sembradas en diversas partes de su obra. Hay que destacar que en esta vertiente jurídico-institucional, el autor que más lo influyó fue R. Hooker con su obra The Laws of Ecclesiastical Polity (1593), ${ }^{39}$ a cuyas reseñas volvía cada vez que debía establecer las relaciones existentes entre Iglesia-Estado. Casi contemporáneamente al sermón de J. Keble, Newman publica en Record newspaper, una serie de artículos sobre: "la Reforma de la Iglesia", cuyos títulos

36 La Iglesia que esbozan los PPS no es una dimensión ideal, sino la configuración histórica en una comunidad, de la obra misteriosa de Dios (Cf. The Church visible and invisible, PPS III, 16; The visible Church an encouragement to faith, PPS III, 17: la Iglesia visible un estímulo para la fe).

37 Newman sostuvo siempre que el sermón de John Keble National Apostasy (1833) había iniciado el movimiento Tractariano; Cf. Meriol Trevor, Newman the Pillar of the cloud, (London: Macmillan \& Co., 1962), 147; Sheridan Gilley, Newman and his Age, (London: Darton Longman and Todd, 2003), 115.

38 Cf. Hervé Savon, Introduzione a Johann Adam Möhler, (Brescia: Queriniana, 1965), 31.

39 La obra Leyes de la Política eclesiástica en el libro quinto desarrolla la eclesiología, y distingue entre mystical Church (mystical body of Christ) y visible Church. 
son reveladores: restauración de la disciplina eclesiástica, sobre su 'respaldo bíblico', la 'aplicación de las doctrinas' y los ‘beneficios de la disciplina'. ${ }^{40}$ En los principios sacramental y dogmático señalados anteriormente, pueden identificarse algunos de los elementos sustanciales de lo que llamamos dimensión jurídica de la Iglesia. ${ }^{41}$ Aunque estas "bases teológicas del derecho" como podemos llamarlas hoy, solo hayan sido enunciadas, constituyen sin embargo en Newman un sistema coherente. En efecto, aplicando la cuarta nota de los desarrollos auténticos, "continuidad lógica", Newman hace una derivación del misterio de la encarnación y deduce el principio sacramental; este hace necesaria la unidad visible en la comunidad de fe, la cual se constituye y sostiene en su historia con elementos que la misma Iglesia descubre en la revelación y que reafirma e interpreta en la constante asimilación de la tradición, tales como: culto visible, ley eclesiástica y autoridad. (The Daily Service, PPS III, 21; Submission to Church authority, PPS III, 14). La afirmación de los elementos externos constituye de este modo el signo visible de la unidad de la Iglesia, pero estos, reclaman un elemento interno individual y subjetivo, en donde Newman ubica el concepto de conciencia. Ésta no constituye una entidad autónoma, sino que está ligada a la verdad de la naturaleza en donde resuena constantemente como un eco la voz de Dios. ${ }^{42}$ Dice Newman en un texto de síntesis que tendría profundas resonancias actuales: "Lo que la conciencia es en la historia de una mente individual, lo es el principio dogmático en la historia del cristianismo. Tanto en un caso como en otro se da la formación gradual de un poder directivo a partir de un principio. La

40 Cf. Apo II.

41 En el período anglicano: Submission to Church authority (Sometimiento a la autoridad de la Iglesia de 1829), PPS III, 14; The strictness of the law of Christ (El rigor de la ley de Cristo: de 1837), PPS 4, 1; Obedience without love, as instanced in the character of Balaam (Obediencia sin amor, el caso de Balaam y su carácter de 1837), PPS IV, 2. En los tres sermones, representativos de otros tantos, se conjuga la necesidad de la ley como disciplina con la cual la Iglesia asegura la fidelidad al mandato evangélico y el amor como espiritu y alma de la ley que sostiene la unidad en su observancia.

42 Dice en un pasaje de su novela Calixta. Retazos del siglo III, refiriéndose a la conciencia: "creo en lo que es más real que el sol, la luna, las estrellas, la tierra con todas sus bellezas y la voz de los amigos" (266); Cf. John Henry Newman, Tracts for the Times, with an introduction and notes by J. Tolhurst, (Leominster: Gracewming, 2013), xix. 
voz de la conciencia es mucho más imperativa al testificar una regla de deber, que exitosa al determinar el deber en casos determinados" (Dev 368). En Newman, la conciencia ocupa un lugar central, ${ }^{43}$ a la hora de reconocer la virtualidad y el alcance que una ley tiene con sus consecuencias eclesiales, aun cuando estas se volvieran contra su persona como sucede con la condena por parte de su obispo del Tract 90, que fue la causa de su dimisión a su cargo en Oxford. ${ }^{44}$

\section{Bibliografía}

Artz, Johannes. Newman Lexikon. Mainz: Matthias-Grünewald-Verlag, 1975.

Attard, Fabio. Conscience in the Parochial and Plain Sermons of John Henry Newman. Malta: MidseaBooks, 2008.

Avery Dulles, Models of the Church. New York: Image Book, 2002.

-, Newman. New York: Continuum, 2002.

Bouyer, Louis. Newman. His Life and Spirituality. New York: Kenedy \& Sons, 1958.

Chadwick, Owen, The Spirit of the Oxford Movement. Tractarian Essays. Cambridge: Cambridge University Press, 1992.

Crosby, John. «Newman on Mystery and Dogma», en Strolz, M. and Binder M. (edd.), Academic Symposium and Celebration of the first Centenary of the Death of John Henry Newman. Rome: Urbaniana University Press, 1991, 37-60.

Hughes, Brian. "Newman's Theology of Bishops", Irish Theological Quarterly, 72 (2007): 201-212.

43 Cf. Fabio Attard, Conscience in the Parochial and Plain Sermons of John Henry Newman, (Malta: MedseaBook, 2008).

44 "Una buena lista de juicios ex cathedra a lo largo de tres años, más una nota no poco severa contenida en una Pastoral de mi obispo, equivalían a una condena de mi Tract y por tanto, un repudio formal a la posibilidad de que la doctrina católica cupiese dentro de la Iglesia anglicana" (Apo 209). 
Lang, Uwe Michael. "Newman and the Fathers of the Church", New Blackfriars 92 (2011): 147-156.

Mauti, Ricardo M. «La recepción de Newman en la teología del siglo $X X »$, Teología 87 (2005): 417-462.

- , «La experiencia religiosa, forjadora de un lenguaje teológico significativo en John Henry Newman», Teología 103 (2010): 133-154.

- Newman peregrino de la verdad. Un camino teológico-espiritual. Buenos Aires: Agape, 2011.

- - «John Henry Newman y el talante 'autobiográfico' de su teología», en Sociedad Argentina de Teología, Dar razón de nuestra esperanza. El anuncio del Evangelio en una sociedad plural., Buenos Aires: Agape 2012, 261-270.

- La unidad de la Iglesia en John Henry Newman. Buenos Aires: Agape, 2018.

Metz, Johann B. La fe en la historia y en la sociedad. Madrid: Cristiandad, 1978.

Rowell, Geoffrey, «Newman and the Anglican Tradition: Reflections on Tractarianism and the Seventeenth-Century Anglican Divines», Louvain Studies 15 (1990) 136-150.

Schneider, Michael. Teología como biografía. Una fundamentación teológica. Bilbao: Desclée de Brouwer, 2000. 